\title{
The path selection model of emergency logistics based on cumulative prospect theory
}

\author{
Yihua Wang ${ }^{1}$, Mengke Yang ${ }^{1 *}$ and Xiaoguang Zhou ${ }^{1}$ \\ ${ }^{1}$ School of Automation, Beijing University of Posts and Telecommunications, Beijing, 100876, P. R. China
}

\begin{abstract}
In recent years, sudden natural disasters occur frequently. Typical emergencies have the characteristics of great uncertainty, large-scale casualty risk, time pressure and urgency, which have a series of serious and sustained impacts on people's production and life. Therefore, after the emergencies, emergency rescue is particularly important for disaster-stricken areas, and the decision-making of emergency logistics is an important part of it. At present, the research on emergency logistics in China focuses on the shortest distribution time, multi-objective decision-making, dynamic path planning, and operational research. It is believed that people are completely rational in making decisions, ignoring people's subjective factors and risk attitudes. From the perspective of decision-makers' risk attitude, this paper studies people's decision-making bias under the condition of incomplete rationality.

Based on previous studies, this paper determines the value coefficient and weight coefficient, and according to the characteristics of emergency logistics, time is selected as the reference point., and A path selection model based on cumulative prospect theory is established. According to the risk attitude, the decision maker is divided into risk preference type and risk avoidance type. Based on the established model, an example is simulated, and the parameters in the model are simulated, and the impact of risk attitude and parameter changes on the final decision-making is analyzed. The simulation results show that the cumulative prospect theory is applicable to the study of emergency logistics decision-making mechanism, and the parameter setting will also have an important impact on the path prospect.
\end{abstract}

\section{Introduction}

In recent years, the frequent occurrence of various types of sudden natural disasters has caused huge casualties and economic losses. Therefore, the study of emergency management has attracted the attention of many scholars at home and abroad. As Chen et al. pointed out ${ }^{[1]}$, typical emergencies are characterized by large uncertainties, many emergencies, large casualties, time constraints, severe resource shortages, large impacts, and disruption of infrastructure support. Emergency events will have a series of serious and continuous impact on people's production and life. Therefore, after the emergencies, the relevant departments need to make corresponding emergency response decisions immediately, and rescue the disaster site. The decision-making of emergency logistics is an important part of it. Most cities, population, industry and agriculture in China are located in the coastal and eastern areas with severe disasters such as meteorology, oceans, floods and earthquakes. Such emergencies, which cause or may cause serious casualties, property damage, ecological damage and serious social hazards, endanger public safety, have generated huge emergency logistics needs.

At present, the research on emergency logistics routing mainly focuses on the shortest distribution time ${ }^{[2]}$, multiobjective decision-making [3], Logistics Intelligence ${ }^{[4]}$, dynamic path planning ${ }^{[5]}$, and operational research ${ }^{[6]}$. Most of them assume that the decision-maker is in a completely rational state when making decisions. However, in real life, the decision-making process of the decision-maker is not completely rational. Risk attitude, anchoring effect and other factors will affect the final decision-making of decision-makers.

Prospect theory refers to the phenomenon that decision makers deviate from the optimal result when making decisions due to irrational factors. It is a reference for people to make future decisions and the most representative method to solve the path selection in uncertain environment. Prospect theory considers people's personality preferences and reference point dependence from the perspective of gains and losses, which provides a new perspective and reference for travelers' travel behavior decision-making ${ }^{[7]}$. At present, the research on the direction of emergency logistics involves less prospects theory, but in reality, the decision-makers may not choose the path completely rationally because of the dynamic changes of the disaster situation, and the decision-makers with different risk attitudes will make different decision-making plans. The cumulative prospect theory further modified and improved the prospect theory. Therefore, based on the cumulative prospect theory, this

*Corresponding author's e-mail: yangmengke@139.com 
paper discusses the impact of time reference points on emergency logistics decision-making.

It has certain theoretical and practical significance for the research of cumulative prospect theory in emergency logistics field. On the one hand, the research enriches the application scenarios of cumulative prospect theory, applies cumulative prospect theory to the modeling of emergency logistics, provides the basis for establishing the theoretical model of emergency logistics comprehensively and accurately, and enriches the theoretical results of existing research. On the other hand, the application of cumulative prospect theory can improve the decisionmaking mechanism of emergency logistics and help to improve the efficiency of rescue.

\section{Cumulative Prospect Theory}

Von Neumann put forward the expected utility theory in $1944^{[8]}$. On this basis, Savage developed the stochastic utility theory [9]. Then, Tversky et al. further proposed the concept of cumulative prospect theory $(\mathrm{CPT})^{[10]}$. The third generation prospect theory (PT3) was proposed by Ulrich Schmidt et al. to explain preference reversal phenomenon ${ }^{[11]}$. Later, the research of prospect theory mostly focused on the selection of reference points.

Prospect theory is a theory that describes and predicts people's behavior in risk decision making. It is inconsistent with traditional expectation theory and expected utility theory. People have different attitudes when facing risks. They become risk seekers in the face of "lost" and become risk averse in the face of "getting". The establishment and change of reference points affect people's sense of gain and loss, which in turn affects people's decision-making. The Cumulative Prospect Theory improves the Prospect theory. The cumulative probability is transformed and used instead of directly using the probability. Cumulative Prospect Theory divides people's decision-making process into two stages, namely editing and evaluation. It proposes that the total value be measured by weight function and value function together.

\subsection{Value function}

Value function, also known as subjective utility function, is used to measure the value of the actual utility value of the path deviating from the reference point. Construct the

$$
\begin{aligned}
& \pi_{n}^{+}=w^{+}\left(p_{n}\right), \pi_{-m}^{-}=w^{-}\left(p_{-m}\right) \\
& \pi_{j}^{+}=\omega^{+}\left(p_{j}+p_{j+1}+\cdots+p_{n}\right)-\omega^{+}\left(p_{j+1}+\cdots+p_{n}\right), 0 \leq \mathrm{j} \leq \mathrm{n}-1 \\
& \pi_{j}^{-}=\omega^{-}\left(p_{-m}+p_{-m+1}+\cdots+p_{j}\right)-\omega^{-}\left(p_{-m}+\cdots+p_{j-1}\right),-\mathrm{m}+1 \leq \mathrm{j} \leq 0 \\
& x_{-m}<x_{-m+1}<\cdots<x_{-1}<0<x_{1}<\cdots<x_{n-1}<x_{n}
\end{aligned}
$$

The prospective value $V_{i}$ of the path $i$ can be expressed as

$$
V_{i}=\sum_{j=1}^{n} \pi_{j}^{+} v\left(x_{j}\right)+\sum_{j=-m}^{0} \pi_{j}^{-} v\left(x_{j}\right)
$$

expression of value function:

$$
v(x)=\left\{\begin{array}{l}
(\Delta x)^{\alpha}, x \geq 0 \\
-\lambda(-\Delta x)^{\beta}, x<0
\end{array}\right.
$$

$x$ represents the result of an uncertain event, $\Delta x>0$ epresents revenue, $\Delta x<0$ represents loss, $\Delta x=0$ means no avoidance coefficient, $\lambda \geq 1$ express loss aversion. In usual, $\alpha=\beta=0.88, \lambda=2.25$.

\subsection{Weighting function}

Weight function is used to simulate human psychological . People tend to overestimate low-probability and are relatively insensitive to changes in intermediateprobabilities. But for very low probability, the weight of 1 is given.

The method of determining weight function proposed by Kahneman and Tversky (1979) ${ }^{[12]}$ is adopted:

$$
\begin{aligned}
& \omega^{+}(p)=\frac{p^{\gamma}}{\left[p^{\gamma}+(1-p)^{\gamma}\right]^{1 / \gamma}} \\
& \omega^{-}(p)=\frac{p^{\delta}}{\left[p^{\delta}+(1-p)^{\delta}\right]^{1 / \delta}}
\end{aligned}
$$

In the formula, $\omega$ is the perceptual probability of event occurrence, $p$ is the actual probability of event occurrence. $\gamma$ and $\delta$ are perceptual probability coefficients, Generally, the perception coefficient is 0.61 when faced with acquisition and 0.69 when faced with loss. The interval method is used to estimate individual subjective probability, and the continuous distribution is discretized into $K$ intervals. The continuous travel time of route $i$ is $\left[a_{i}, b_{i}\right]$, So the length of each interval is $\left(b_{i}-a_{i}\right) / k$, In order to calculate conveniently, the end-point value of the interval satisfying the probability of travel the $(0.01,0.99)$ is selected in route $i$, and the Assuming that interval are obtained.

Assuming that an uncertain scheme consists of a series of combinations $\left(x_{j,} p_{j}\right)$, and $-m \leq j \leq n$.

\subsection{Time reference point}

Due to the different risk attitudes of decision makers, the reliability of delivery time is also different. Time-based reliability defines reference points. Assuming that the probability of minimum delivery time $t_{\min }^{i}$ of route $i$ is not less than reliability $\rho$, The minimum $t_{\min }^{i}$ satisfying the 
reliability requirement is selected as the time reference point $t_{0}$. Assuming that the travel time distribution of the route satisfies the normal distribution $N_{i}\left(\mu_{i}, \sigma_{i}^{2}\right)$, then $t_{\min }^{i}=\min \left\{\phi^{-1}(\rho)\right\}$.

In emergency logistics, the sooner materials arrive at the disaster site, the less damage they will cause. So when $t_{i} \leq t_{0}$ gains, $t_{i}>t_{0}$ loses.

\section{Example analysis}

A simple simulation example is used to validate the above model and discuss what decision-makers will make on the basis of different time reliability.

It is assumed that there are three paths from point $\mathrm{O}$ of distribution center to point $\mathrm{Q}$ of emergency demand. The parameters of each path are shown in table 1 . It is assumed that the travel time of three paths obeys normal distribution. In order to compare the impact of time reliability on results, decision makers are divided into risk preference and risk aversion according to risk attitude. The time reliability of risk preference decision maker is not less than 0.3 , and that of risk aversion decision maker is not less than 0.8 .

Table 1. Path parameters.

\begin{tabular}{|c|c|}
\hline Path & Travel time distribution \\
\hline 1 & $N(250,2500)$ \\
\hline 2 & $N(260,100)$ \\
\hline 3 & $N(310,900)$ \\
\hline
\end{tabular}

According to the calculation, the time reference points and cumulative prospect values of different risk decision makers are shown in table 2.

Table 2. Time reference points and path outlook values for decision makers.

\begin{tabular}{|c|c|c|c|}
\hline $\begin{array}{l}\text { Decision } \\
\text { maker }\end{array}$ & Path & $\begin{array}{c}\text { Time reference } \\
\text { point }\end{array}$ & $\begin{array}{c}\text { Prospect } \\
\text { value }\end{array}$ \\
\hline \multirow{3}{*}{$\begin{array}{c}\text { Risk } \\
\text { preference }\end{array}$} & Path & \multirow{3}{*}{223.78} & -40.16 \\
\hline & $\begin{array}{c}\text { Path } \\
2\end{array}$ & & -48.16 \\
\hline & $\begin{array}{c}\text { Path } \\
3\end{array}$ & & -102.93 \\
\hline \multirow{3}{*}{$\begin{array}{c}\text { Risk } \\
\text { aversion }\end{array}$} & $\begin{array}{c}\text { Path } \\
1\end{array}$ & \multirow{3}{*}{268.42} & -2.87 \\
\hline & $\begin{array}{c}\text { Path } \\
2\end{array}$ & & 3.38 \\
\hline & $\begin{array}{c}\text { Path } \\
3\end{array}$ & & -52.87 \\
\hline
\end{tabular}

From the results of table 2, we can see that for decision makers with time as reference point, the choice of risk preference decision makers is path 1 , but for evasive decision makers, the best choice is path 2 .

According to the analysis of the above results, decision makers with different risk attitudes will show different results in the face of possible choices. Even in the case of high risk, risk-preference decision-makers tend to choose short-time paths. For evasive decision-makers, when the mean difference of travel time is small, the path with small risk coefficient is preferred. However, when the mean difference is too large, the final decision of the decision maker is mainly affected by the mean.

In order to further investigate the relationship between the final decision of the decision maker and mean and variance, we assume that there is a path 4 , and the travel time distribution satisfies $N(260,900)$. We calculate the prospect value in the case of path 4 , and compare it with paths 1 and 2 . The results are shown in table 3 .

Table 3. Time reference points and path prospect values for decision makers.

\begin{tabular}{|c|c|c|c|}
\hline \multirow{2}{*}{$\begin{array}{c}\text { Decision } \\
\text { maker }\end{array}$} & Path & \multirow{2}{*}{$\begin{array}{c}\text { Time } \\
\text { reference } \\
\text { point }\end{array}$} & $\begin{array}{c}\text { Prospect } \\
\text { value }\end{array}$ \\
\hline \multirow{2}{*}{$\begin{array}{c}\text { Risk } \\
\text { preference }\end{array}$} & Path 1 & \multirow{2}{*}{223.78} & -40.16 \\
\cline { 2 - 2 } & Path 2 & -48.16 \\
\cline { 2 - 2 } $\begin{array}{c}\text { Risk } \\
\text { aversion }\end{array}$ & Path 4 & & -46.82 \\
\cline { 2 - 2 } & Path 1 & Path 2 & -2.87 \\
\cline { 2 - 2 } & Path 4 & & 3.38 \\
& & & -3.85 \\
\hline
\end{tabular}

It is shown that the final decision of decision makers with different risk preferences is related to the mean and variance of the path. When the mean is the same, the risk preference decision-makers show a certain risk pursuit; When the variance difference is large, evasive decisionmakers may tend to choose a more stable travel path, and when the variance gap is not large, the travel path with a smaller mean value will be selected.

\section{Parameter analysis}

The above conclusions are obtained by determining the values of parameters such as $\alpha$ and $\beta$. In practice, the different values of each parameter make the prospect values change accordingly. Next, take Path 1 as an example, use MATLAB to simulate the parameters, and discuss the impact of parameter changes on the path prospects.

Firstly, we consider changing the parameters of value function, $\alpha$ and $\beta$. Results are shown in figure 1 , figure 2 . 


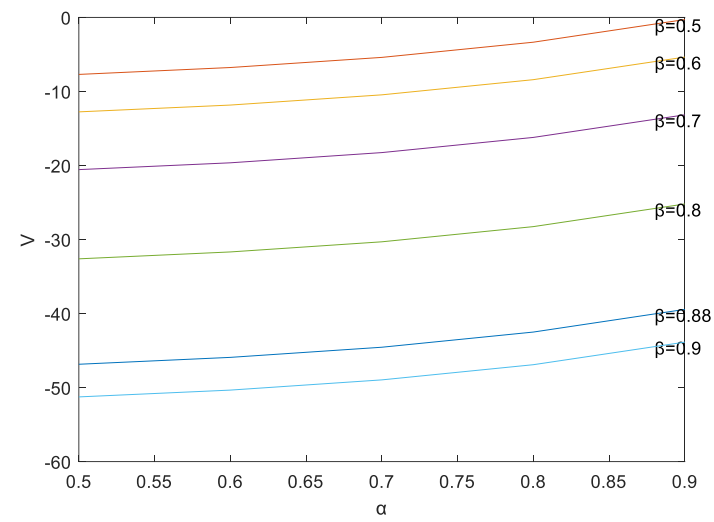

Figure 1. Relationship between prospect value and $\alpha, \beta$ of risk preference decision makers.

From the figure, we can see that with the increase of $\alpha$, the path prospect values show an increasing trend, while with the increase of $\beta$, the path prospect values show a downward trend. This shows that the increase of revenue sensitivity coefficient and the decrease of loss sensitivity coefficient will lead to the optimization of the results. With the increase of coefficients, the change range of path

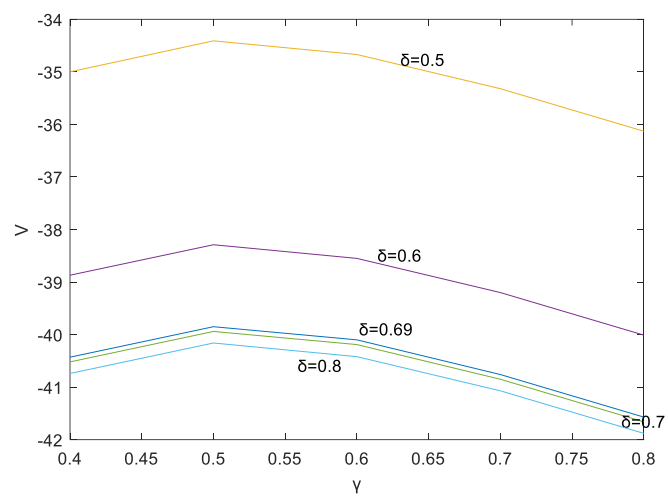

Figure 3. Relationship between prospect value and $\gamma, \delta$ of risk preference decision makers.

It can be seen from the figure that as the $\gamma$ increases, the prospect value of the decision maker's path increases first and then decreases. This shows that for the decision makers, when the acquired perception reaches a certain level, increasing the acquired perception will not produce better results, but will cause the result to develop in a bad direction, and increasing the loss perception will definitely make the result even worse.

For risk preference decision makers, with the increase of $\delta$, the path prospect value decreases, and the decline gradually decreases. For risk-averse decision makers, as $\delta$ increases, the path prospect value increases and grows. In the face of stronger loss of perception, preference decision makers are more likely to produce worse results because they have certain risk pursuits, while evasive decision makers first choose to avoid risks and will choose a more conservative strategy, so instead have better results.

Similar to the parameter variation law of the value function, the evasive decision makers always change more than the preference decision makers. This phenomenon shows once again that people are less sensitive to gain than

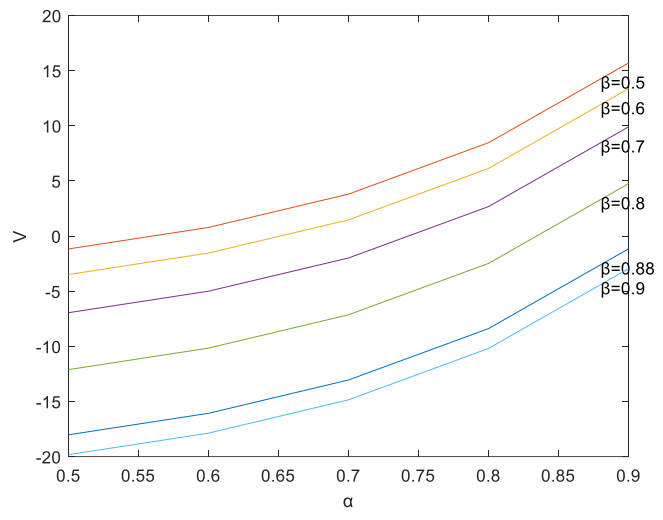

Figure 2. Relationship between prospect value and $\alpha, \beta$ of riskavoiding decision makers.

prospect value also shows an increasing trend, and the change range of evasive decision-makers is larger, which indicates that decision-makers are more sensitive to loss.

Then consider changing the parameters of the weight function $\gamma$ and $\delta$. Results are shown in figure 3, figure 4.

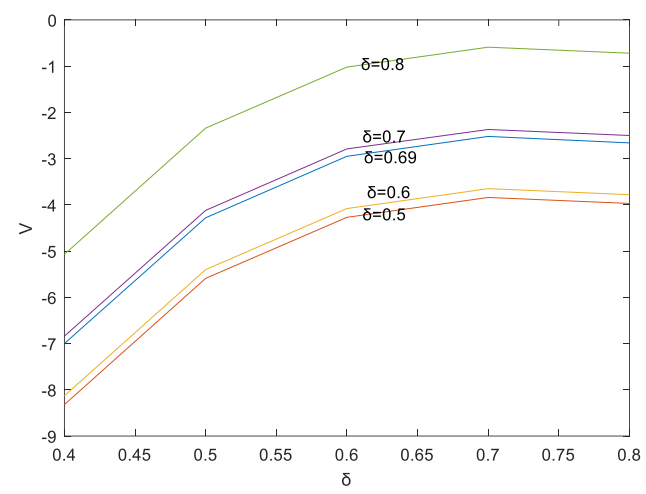

Figure 4. Relationship between prospect value and $\gamma, \delta$ of riskavoiding decision makers.

loss.

\section{Conclusion}

Considering the uncertainty of emergencies and the urgency of emergency logistics, this paper uses the cumulative prospect theory to analyze the differences in path selection between different types of decision makers and the possible causes of these differences.

In this paper, through the simulation example, Using the cumulative prospect theory, specific data of different paths is used to quantify the decision maker's decision results into prospect values. According to the simulation results of the four paths, we draw the following conclusions: Different types of decision makers have different perceptive values for the same path, and the results are also different. Risk-preferred decision makers tend to choose paths with short time and certain risk, even at the same time, they are more willing to choose paths with slightly higher risk; risk-averse decision makers 
prefer to choose paths with high reliability, which is based on the fact that there is little difference in time, when the time difference is large, the short time is still the dominant factor of choice.

At the end of the example analysis, we analyze the parameters of the single path. It is concluded that the influence of parameter changes on decision-making results is as follows: for value function, increasing revenue sensitivity coefficient or decreasing loss sensitivity coefficient will increase the prospect value of the final path; For the weight function, increasing the perceived gain does not necessarily make the result better. When the perceived gain reaches a certain level, increasing the perceived gain will make the result worse, while increasing the perceived loss will make the result worse. In the face of stronger loss perception, risk-preference decision makers will reduce their prospect value because they pursue risk. Risk-averse decision makers choose more risk aversion to improve their prospect value, which is also in line with the actual situation. In either case, the range of change of evasive decision-makers is always greater than that of preferential decision-makers, In other words, decision makers are more sensitive to losses.

On the basis of cumulative prospect theory, this paper analyses the possible decision-making differences among decision makers with different risk preferences, applies cumulative prospect theory to the actual situation of emergency logistics, and verifies it by simulation. This paper has certain theoretical and practical significance, and provides a new direction for the possibility of path selection, but research also has certain limitations. The study only takes time as a single reference point, and does not consider the possible impact of other factors, such as the dynamic change of the path, the traffic volume of the road section, the traffic situation, etc., so the application of cumulative prospect theory in emergency logistics needs further research.

\section{Acknowledge}

After continuous efforts and unremitting perseverance, the paper was finally completed. Thank my mentor, Dr. Yang. In the process of writing papers, Dr. Yang has always given guidance, devoted herself to me, always full of hope for me, encouraged and supported me to complete the paper creation. Thank you for your guidance and help in the process of writing papers. Thanks to other teachers and students in the lab for their careful guidance and help in the process of thesis writing.

This research were funded by National Key Research and Development Program of China, grant number 2016YFC0803206, and Fundamental Research Funds of Beijing University of Posts and Telecommunications, grant number 2018XKJC07,2018RC27.

\section{Reference}

1. Chen, R., Sharman, R., Rao, H. R., \& Upadhyaya, S. J. (2008). Coordination in emergency response management. Communications of the ACM, 51(5), 66-73.
2. GAO, H. H., \& TANG, C. (2014). Emergency Logistics Path Planning Based on the Shortest Delivery Time. Logistics Engineering and Management, (2), 36.

3. Liu, H., Wang, W., \& Zhang, Q. (2012). Multiobjective location-routing problem of reverse logistics based on gra with entropy weight. Grey Systems: Theory and Application, 2(2), 249-258.

4. Yang M, Zhou X, Shafaq S, et al (2017) . Design and Implementation of Cloud Platform for Intelligent Logistics in the Trend of Intellectualization. China Communications, 14 (10), 180-191

5. Sheu, J. B. (2010). Dynamic relief-demand management for emergency logistics operations under large-scale disasters. Transportation Research Part E Logistics \& Transportation Review, 46(1), 017.

6. Sheu, J. B. (2007). An emergency logistics distribution approach for quick response to urgent relief demand in disasters. Transportation Research Part E: Logistics and Transportation Review, 43(6), 0709.

7. Lin, Z, \& Chen, Z. X. (2006). A prospect theory-based route choice model of traveler with prior information. Journal of Transportation Systems Engineering \& Information Technology, 6(2), 42-46.

8. Neumann, J. V., \& Morgenstern, O. (1944). The Theory of Games and Economic Behaviour. Princeton University Press Publishing, Princeton.

9. Savage, L. (1954). The Foundations of Statistics. JOHN WILEY Publishing, Hoboken.

10. Kahneman, A. T. (1992). Advances in prospect theory: cumulative representation of uncertainty. Journal of Risk and Uncertainty, 5(4), 297-323.

11. Zank, U. S. (2005). What is loss aversion?. Journal of Risk and Uncertainty, 30(2), 157-167.

12. Tversky, K. A. (1979). Prospect theory: an analysis of decision under risk. Econometrica, 47(2), 263-292. 